\title{
Study of Ruminant Fasciolosis in Selected Districts in Upper Awash River Basin, South Western Shoa, Ethiopia
}

\author{
Melaku Taye ${ }^{1}$, Teshome Jagema ${ }^{2}$, Asefa Tadese ${ }^{3}$, Endalu Mulatu ${ }^{4}$, Kumela Lelisa ${ }^{5}$ and Delesa Damena ${ }^{6 *}$ \\ ${ }^{1}$ South West Shoa Livestock Development and Fishery Office, Woliso, Oromia, Ethiopia \\ ${ }^{2}$ Oromia Livestock Development and Fishery Office, Finfinne, Oromia, Ethiopia \\ ${ }^{3}$ Ambo University, College of Agriculture, Ambo, Oromia, Ethiopia \\ ${ }^{4}$ Bedelle College of Agriculture and Forestry, Mettu University, Bedelle, Oromia, Ethiopia \\ ${ }^{5}$ National Institute for Control and Eradication of Tsetse Fly and Trypanomosis, Addis Ababa, Ethiopia \\ ${ }^{6}$ National Animal Health Diagnostic and Investigation Center, Sebeta, Oromia, Ethiopia
}

\begin{abstract}
A cross-sectional study was conducted in February 2013 to determine the prevalence of fasciolosis in cattle and sheep in areas adjacent to the upper Awash River basin, South Western Shoa, Ethiopia. A total of 399 (308 bovine and 91 ovine) faecal samples were collected from Illu and Sebeta Hawas districts and microscopically examined using sedimentation techniques. Eggs of Fasciola species were identified based on their characteristic morphology and colour. Besides, a gross pathological examination was conducted on a total of 237 livers of slaughtered animals at Sebeta municipal abattoir to identify Fasciola species and assess the extent of infection. Coprological examinations revealed that, significantly higher prevalence $(48.4 \%)$ in sheep than in cattle $(36.7 \%)$. Similarly, a prevalence rate recorded in Illu district $(45.6 \%)$ was significantly higher than that of Sebeta Hawas district $(34.7 \%)$. Out of a total of 237 livers examined, $38.4 \%(91)$ were infected by one or more Fasciola species. The majority (54.9\%) of the infection was caused by $F$. hepatica followed by $F$. gigantica $(28.6 \%)$ and mixed species $(16.5 \%)$. This study showed that, fasciolosis is exerting a significant impact on livestock production and productivity in the study areas. Therefore, proper control scheme should be designed and implemented in areas adjacent to the upper Awash River basin to minimize the burden of fasciolosis.
\end{abstract}

Keywords: Prevalence; Fasciolosis; Bovine; Ovine; South West Shoa; Ethiopia

\section{Introduction}

Ethiopia is endowed with high livestock population with 54 million heads of cattle and 25.5 million sheep; the large proportions of which are kept in traditional extensive production system [1]. Despite the large population of animals, productivity in Ethiopia is low and below the average compared to most countries in Sub-Saharan Africa. This is mainly due to poor nutrition, reproduction insufficiency, management constraints and animal diseases [2].

Fasciolosis is one of the most important parasitic diseases that hamper livestock production in Ethiopia [3]. F. hepatica (the high land) and F. gigantica (low land) types of liver flukes cause severe economic losses in different parts of the country. Effects of fasciolosis are usually expressed in terms of liver condemnation at slaughter houses, infertility, reduction in traction power and low weight at birth and mortality [47]. It occurs in water logged and marshy grazing areas, particularly along the Abay (Blue Nile) river basin. It is also highly prevalent in the high land and low land areas of Oromia regional state [2]. The intermediate hosts for both F. hepatica and F. gigantica are snails of the family Lymnaesidae. L. truncatula is the most important and common intermediate host for F. hepatica in different parts of Ethiopia [4]

Understanding the local epidemiology of fasciolosis could help to device and implement effective control programs [8]. Sebeta Hawas and Illu districts also known as Bacho, constitute a significant part of the upper Awash River basin. In these districts, Awash River is known to cause annual over flooding of wide areas during long Ethiopian rainy season leaving large water bodies and swampy areas for an extended period into the dry season. Although this creates a favourable environment for breeding of snail hosts, information is lacking on the extent and magnitude of Fasciolosis in the areas. Therefore, this study was initiated with the aim of determining the prevalence of bovine and ovine fasciolosis and assessing associated risk factors in Sebeta Hawas and Illu districts of central Ethiopia.

\section{Materials and Methods}

\section{Study location}

The study was carried out in Sebeta Hawas and Ellu districts of South Western Shoa, located adjacent to uplands of the Awash River basin, $50 \mathrm{kms}$ west of Addis Ababa. The area has an altitude of 18003385 meters above sea level (masl) and is characterized by long rainy season (June - September), short rainy season (March- may) and a dry season (October- January). The average annual rain fall, annual temperature and relative humidity are $866-1200 \mathrm{~mm}, 11.3-28^{\circ} \mathrm{C}$ and 49.3\% respectively. Awash River floods the areas during the long Ethiopian rainy season and leave large water bodies and swampy places for an extended period into the dry season. Mixed agriculture is the mainstay of the livelihood of the society where crop and livestock production play integral roles. Small scale irrigation is wide spread for production of cash crops in the areas.

\section{Study animals}

The study population constituted of indigenous zebu cattle and sheep. The animals are kept under traditional extensive husbandry system with communal grazing lands and watering points. Animal

*Corresponding author: Delesa Damena, National Animal Health Diagnostic and Investigation Center, Sebeta, PO Box 04, Oromia, Ethiopia, Tel: +251911771998; E-mail: delesa_damenaa@yahoo.com

Received July 10, 2016; Accepted August 02, 2016; Published August 08, 2016

Citation: Taye M, Jagema T, Tadese A, Mulatu E, Lelisa K, et al. (2016) Study of Ruminant Fasciolosis in Selected Districts in Upper Awash River Basin, South Western Shoa, Ethiopia. J Vet Sci Technol 7: 368. doi :10.4172/2157-7579.1000368

Copyright: ( $) 2016$ Taye M, et al. This is an open-access article distributed under the terms of the Creative Commons Attribution License, which permits unrestricted use, distribution, and reproduction in any medium, provided the original author and source are credited. 
population of the district consisted of 33,610 cattle, 1,945 goats, 6,202 sheep, and 6,753 equines.

\section{Sampling and sample size determination}

A cross-sectional study was conducted in February 2013 to estimate the prevalence of fasciolosis and assess associated risk factors. The study sites were selected based on their accessibility to transport and availability of suitable habitat for snail host and the parasite. Owners were informed one day a head of sample collection to gather their animals at one place and simple random sampling technique was employed to select the study from the population. The sample size required was calculated at $50 \%$ prevalence with level of precision at $5 \%$ and $95 \%$ confidence interval using a formula described by Thrusfield [9]. As the actual prevalence was unknown, $50 \%$ was used to produce the largest sample size possible. Therefore, a total of 384 animals were needed to sample. However, a total of 399 (308 cattle and 91 sheep) were sampled to increase the precision of the study. Age, sex and body condition score of the studied animals were recorded during sampling. The age was estimated by means of dentition. Cattle were grouped as calf (up to 1 year), young (1-3 years) and adult above 3 years while sheep were grouped as lamb (up to 6 months), young (612 months) and adult above 1 year [10]. The body condition status of selected animals was assessed and ranked as good, medium and poor [11]. Besides, growth pathological examination was conducted on 237 bovine livers at Sebeta municipal abattoir.

\section{Coprological study}

For coprological examination, faecal samples were collected directly from rectum early in the morning, preserved in $10 \%$ formalin and transported to the National Animal Health Diagnostic and Investigation Centre (NAHDIC) for laboratory diagnosis. Faecal examination for Fasciola eggs was carried out using sedimentation method as described by Hansen and Perry [12]. 2 grams of faeces was added to $42 \mathrm{ml}$ of water in a graduated cylinder. The contents were then mixed thoroughly using a glass rod, and were poured through a tea strainer to remove large debris. The solution was then further passed through a sieve (mesh aperture $210 \mathrm{~mm}$ ) into a conical flask and water was run through the sieve to ensure no eggs remained attached to the sieve. The filtrate was then allowed to sediment for $3 \mathrm{~min}$ after which the supernatant was siphoned off taking care not to disturb the precipitated matters. The latter was stained with two drops of methylene blue and the entire sediment placed on slide covered with a cover slip and viewed under a compound microscope (Labomed). Eggs of Fasciola species were identified by their characteristic morphology and colour.

\section{Abattoir survey}

In abattoir survey, livers of slaughtered animals were registered and examined according to the description given by Dwinger et al. [13]. The affected liver was designated as lightly affected: if none or only enlarged bile duct was seen or if the quarter of the liver was affected before cutting on the visceral surface, cutting reveals enlarged bile ducts and/ or flukes. Moderately affected: If half of the organ was affected and more than one enlarged bile ducts were visible before cutting. Severely affected: If the entire organ was involved or if the liver was cirrhotic. Additionally, the gall bladder was removed from the rest of the liver and the contents were checked for the presence of adult Fasciola species. The bile duct was carefully opened with scissors and searched for adult flukes. The rest of the liver was cut into an approximate size of $1 \mathrm{~cm}$ thick slices and pressed between fingers to expose flukes lodged in small liver ducts. Identification of recovered fluke species was done as described by Urquhart et al. [14].

\section{Data analysis}

Raw data were entered into a Microsoft Excel spreadsheet and descriptive statistics were used to summarize the data. STATA version 11.0 statistical software programs were used to analyze the data. The prevalence was calculated for all data as the number of infected positives divided by the total number examined and multiplied by 100 . The association between the prevalence of Fasciolosis and risk factors were assessed by chi-square test $\left(\chi^{2}\right)$. The test result was considered significant when the calculated $\mathrm{p}$-value was less than 0.05 at $95 \%$ confidence interval.

\section{Results}

An overall prevalence of $36.7 \%$ (113/399) was recorded in this study. The prevalence of fasciolosis was significantly higher in ovine species $(48.4 \%)$ than in bovine species $(36.7 \%)$ as shown in Table 1. Similarly, a prevalence recorded in Illu district (45.6\%) was significantly higher than that of Sebeta Hawas district (34.7\%) (Table 2).

In abattoir survey, out of a total of 237 livers examined, 38.4\% (91) were infected by one or more Fasciola species. The majority (54.9\%) of the infection was caused by F. hepatica followed by F. gigantica (28.6\%) and mixed species (16.5\%) as shown in Table 3. The majority $(48.5 \%)$ of the infected livers were moderately affected (Table 4 ). Variables such as age and sex were not significantly associated with the prevalence of fasciolosis.

\section{Discussions}

The current study revealed that fasciolosis is among economically important diseases in the study area. Coprological examination revealed a prevalence rate of $36.7 \%$ in cattle and $48.4 \%$ in sheep. This finding is higher than the results of most of the earlier studies in Ethiopia $[15,16]$. However, studies in different parts of Ethiopia showed a huge variation of prevalence rate ranging from $20.3 \%$ to $90.7 \%$ [8,17-19]. This disparity could have been attributed to the differences in climatic and ecological conditions, study methodology and sampling strategy. In addition to the variations in climatic and ecological conditions, the seasons in which the studies were conducted could contribute to the variations that exist among different findings in different areas [20]. In dry seasons, snails are forced to undergo aestivation deep in the mud in search of moisture. Only those snails in permanent water source have the opportunity to shed cercariae and hence low prevalence rate in dry season [20,21].

The higher prevalence recorded in dry season in this study suggests the presence of a suitable habitat for breeding of the snails and development of the parasites throughout the year. In addition to the presence of large swampy areas, the presence of small scale irrigation in some places could have been contributed in making favourable environment for snails; consequently leading to the wide spread distribution of the disease. Irrigation has a huge potential to facilitate transmission of water borne human and animal diseases. Aquatic or amphibian intermediate host transmit diseases such as malaria, fasciolosis and shistosomiasis [22].

The prevalence in Illu district (45.6\%) was significantly higher than that of Sebeta Hawas district (34.7). This could be due to the presence

\begin{tabular}{|c|c|c|c|c|}
\hline Species & $\mathbf{n}$ & Positives & Prevalence (\%) & P-value \\
\hline Bovine & 308 & 113 & 36.7 & 0.03 \\
\hline Ovine & 91 & 44 & 48.4 & \\
\hline
\end{tabular}

Table 1: Prevalence of fasciolosis in Sebeta Hawas and Ellu districts of south west shoa, Ethiopia. 
Citation: Taye M, Jagema T, Tadese A, Mulatu E, Lelisa K, et al. (2016) Study of Ruminant Fasciolosis in Selected Districts in Upper Awash River Basin, South Western Shoa, Ethiopia. J Vet Sci Technol 7: 368. doi :10.4172/2157-7579.1000368

Page 3 of 4

\begin{tabular}{|c|c|c|c|c|c|c|c|}
\hline Species & Variable & Category & $\begin{array}{l}\text { Number } \\
\text { examined }\end{array}$ & Number of Positive & Prevalence (\%) & Chi-sq result & $P$-value \\
\hline \multirow{3}{*}{ bovine } & Age & $\begin{array}{l}\text { Calf } \\
\text { Young } \\
\text { Adult }\end{array}$ & $\begin{array}{c}24 \\
66 \\
218\end{array}$ & $\begin{array}{c}7 \\
26 \\
80\end{array}$ & $\begin{array}{l}29.2 \\
39.4 \\
36.7\end{array}$ & 0.793 & 0.673 \\
\hline & Sex & $\begin{array}{l}\text { Female } \\
\text { Male }\end{array}$ & $\begin{array}{l}132 \\
176\end{array}$ & $\begin{array}{l}50 \\
63\end{array}$ & $\begin{array}{l}37.9 \\
35.8\end{array}$ & 0.141 & 0.707 \\
\hline & Site & $\begin{array}{c}\text { Sebeta } \\
\text { Ellu }\end{array}$ & $\begin{array}{l}166 \\
142\end{array}$ & $\begin{array}{l}52 \\
61\end{array}$ & $\begin{array}{l}31.3 \\
43.0\end{array}$ & 4.458 & 0.035 \\
\hline \multirow{3}{*}{ ovine } & Age & $\begin{array}{l}\text { Lamb } \\
\text { Young } \\
\text { Adult }\end{array}$ & $\begin{array}{l}21 \\
25 \\
45\end{array}$ & $\begin{array}{c}9 \\
13 \\
22\end{array}$ & $\begin{array}{c}42.9 \\
52 \\
48.9\end{array}$ & 0.392 & 0.822 \\
\hline & Sex & $\begin{array}{l}\text { Female } \\
\text { Male }\end{array}$ & $\begin{array}{l}52 \\
39\end{array}$ & $\begin{array}{l}25 \\
19\end{array}$ & $\begin{array}{l}48.1 \\
48.7\end{array}$ & 0.004 & 0.925 \\
\hline & Site & $\begin{array}{c}\text { Sebeta } \\
\text { Ellu }\end{array}$ & $\begin{array}{l}62 \\
29\end{array}$ & $\begin{array}{l}27 \\
17\end{array}$ & $\begin{array}{l}43.5 \\
58.6\end{array}$ & 1.797 & 0.180 \\
\hline
\end{tabular}

Table 2: Associations of different risk factors with ruminant fasciolosis assessed by Chi-square.

\begin{tabular}{|c|c|c|} 
Species of parasite & Number of liver (\%) & P value \\
\hline F. gigantica & $26(28.8 \%)$ & \\
F. hepatica & $50(54.9 \%)$ & 0.045 \\
\hline Mixed infection & $15(16.5 \%)$ & \\
\hline
\end{tabular}

Table 3: Relative distribution of Fasciola species among examined livers.

\begin{tabular}{|c|c|c|c|}
\hline Lesions & $\mathbf{n}$ & $\%$ & $\begin{array}{c}\text { Average fluke } \\
\text { burden }\end{array}$ \\
\hline Light & 27 & $29.7 \%$ & 39.1 \\
\hline Moderate & 44 & $48.5 \%$ & 80.0 \\
\hline Severe & 20 & $21.8 \%$ & 53.5 \\
\hline Total & 91 & $100 \%$ & 57.5 \\
\hline
\end{tabular}

Table 4: Degree of liver lesion and average fluke burden

of relatively larger swampy areas in Illu district resulting from over flooding of Awash River during the rainy season. These areas remain wet for long periods during the dry season. Swampy areas are favourable for breeding of snails $[4,14,20]$. Seasonal movement of animals could also play an important role in the epidemiology of fasciolosis in this district. During the rainy season, animals move to the neighbouring hill side (high lands) for grazing and move back during the dry season to the marshy lands in search of pasture.

In this study, the prevalence of fasciolosis in sheep (48.3\%) was significantly higher than that of cattle (36.7\%). Variations between different species (bovine and ovine) could have been arisen from the differences in host susceptibility to the infection. Sheep's don't normally develop a protective immune response to reinfection while cattle have the ability of developing protection against reinfection with Fasciola species [20]. The prevalence rate in between different sex and age groups showed no significant variations. Similar finding was reported from Ethiopia $[23,24]$. This indicates that both sexes and different age groups are equally susceptible to fasciolosis.

In the current abattoir survey, out of a total of 237 livers examined, $38.4 \%$ (91) were infected by one or more Fasciola species. The majority $(54.9 \%)$ of the infection was caused by $F$. hepatica followed by F. gigantica (28.6\%) and mixed species (16.5\%). Consistent to our findings, abattoir surveys in different parts of Ethiopia reported the predominance of $F$. hepatica over $F$. gigantica $[17,18,25,26]$. This might be associated with the existence of favourable ecological conditions for lymnea truncatula, the intermediate host for F. hepatica [14]. Floodprone areas and low lying marshy and drainage ditches are ideal for breeding of lymnea truncatula [20].

In this study, the fluke count in moderately affected livers was higher than the count in severely affected livers. This could be due to severe fibrosis in the latter that potentially impede the movements of immature flukes; making the liver less attractive to newly the invading flukes [20]. A high fluke burden (57.5 per affected liver) was recorded in this study. This finding was in close agreement with earlier studies in Ethiopia [15,27]. Presence of more than 50 flukes per liver indicates high pathogenicity [17]. The more flukes an animal has, the more blood it losses and the more anaemic it becomes [14].

In conclusion, fasciolosis is a wide spread ruminant health problems and cause significant economic losses both in terms of production loss and liver condemnation in the study areas. This study provides important information on epidemiology of ruminant fasciolosis and highlights the urgency of proper intervention strategy to minimize the burden of the disease.

\section{References}

1. Central Statistical Agency (2013) Agricultural Sample Survey (2012/13) Volume II. Report on Livestock and Livestock Characteristics. Statistical Bulletin, 570. Addis Ababa, Ethiopia.

2. DACA (2006) Standard Veterinary Treatment Guideline for Veterinary practice 1st edn. Drug Administration and Control Authority, Addis Ababa, Ethiopia.

3. OIE (2011) World Animal Health Information Database (WAHID) Interface.

4. Graber MM (1975) Helminths and Helminthiasis of different domestic and wild animals of Ethiopia. Bulletin of Animal Health and production in Africa 23: 57-86.

5. Adem A (1994) Prevalence of bovine and ovine fasciolosis: A preliminary survey around Ziway Region (Shewa). DVM Thesis, Faculty of Veterinary Medicine Addis Ababa University Debre Zeit, Ethiopia.

6. Ngategize PK, Bekele T, Tilahun G (1993) Financial losses caused by ovine fasciolosis in the Ethiopian highlands. Trop Anim Health Prod 25: 155-161.

7. Njau BC, Scholtens RG (1991) The role of traditional harvested hay in the transmission of ovine fasciolosis in Ethiopian highlands. Vet Res Com 15: 369 372.

8. Yilma JM, Malone JB (1998) A geographic information system forecast model for strategic control of fasciolosis in Ethiopia. Vet Parasitol 78: 103-127.

9. Thrusfield M (2005) Veterinary Epidemiology. 3rd edn. Blackwell Science, Oxford, UK, Pp: 233

10. Pasquini C, Spurgeon T, Pasquini S (2003) Anatomy of Domestic Animals: Systemic and Regional Approach. 10th edition. Sudz Publishing, USA, Pp: 255

11. Nicholson MJ, Butterworth MH (1986) A guide to condition scoring of Zebu cattle. International Livestock Center for Africa (ILCA), Addis Ababa, Ethiopia.

12. Hanson J, Perry B (1994) The Epidemiology, Diagnosis and Control of Helminth Parasites of Ruminants. A Hand Book. International Laboratory for Research on Animal Diseases. Food and Agricultural Organization of the United Nations Rome, Italy, Pp: 72-89.

13. Graber MM (1975) Helminths and helminthiasis of domestic and wild animals of Ethiopia. Bull Anim Health Prod 23: 57-86. 
Citation: Taye M, Jagema T, Tadese A, Mulatu E, Lelisa K, et al. (2016) Study of Ruminant Fasciolosis in Selected Districts in Upper Awash River Basin, South Western Shoa, Ethiopia. J Vet Sci Technol 7: 368. doi :10.4172/2157-7579.1000368

14. Armour JL, Duncan JL, Dunn AM, Jennings FW, Urquhart GM (1997) Veterinary Parasitology. 2nd edn. Blackwell Publishers, London, UK, Pp: 103-113.

15. Sintayehu M (2007) Bovine fasciolosis in and around sebeta on field and abattoir survey in Ethiopia.

16. Hymanot A (1990) Prevalence survey of Bovine Fasciolosis in Easte Hararghe administrative region. DVM thesis, Faculty of Veterinary Medicine, Addis Ababa, Debre Zeit, Ethiopia. Pp: 21

17. Aragaw K, Negus $Y$, Denbarga $Y$, Sheferaw D (2012) Fasciolosis in slaughtered cattle in Addis Ababa Abattoir, Ethiopia. Global Vet 8: 115-118.

18. Berhe G, Berhane K, Tadesse G (2009) Prevalence and economic significance of fasciolosis in cattle in Mekelle Area of Ethiopia. Trop Anim Health Prod 41: 1503-1505.

19. Woldemariam S, Wossene A (2007) Effects of a strategic anthelmintic treatment intervention bovine Fasciolosis: A study conducted in facilities endemic area in north western Ethiopia. Ethiop Vet J 11: 59-68.

20. Soulsby FJL (1982) Helminths, Arthropoda and Protozoa of domestic animals. 7th edn. Lea and Febiger, $\mathrm{Pp}: 44-51$.
21. Constable PD, Hinchcliff KW, Gruenberg W, Done SH (1994) A text book of the disease of cattle, sheep, goats, pigs and horse: Veterinary Medicine. 8th edn. Elsevier Health Sciences, London, UK. Pp: 1015-1026.

22. Traore A (1989) Incidence and control of faciolosis around Niono, Central Mali. ILCA Bulletin No. 33, Pp: 18-20.

23. Yehenew M (1985) Prevalence of Fasciolosis at Gondor clinic in and around Lake Tana. DVM thesis, Faculty of Veterinary Medicine, Addis Ababa University, Debre Zeit, Ethiopia. Pp: 25.

24. Dagne M (1994) Survey on prevalence and economic significance of bovine Fasciolosis in Debre Berhan Region. DVM Thesis, Addis Ababa University, Debre Zeit, Ethiopia.

25. Tolosa T, Tigre W (2007) The Prevalence and Economic Significance of Bovine Fasciolosis at Jimma Abattoir, Ethiopia. The Internet J Vet Med, p: 3.

26. Ibrahim NP, Wasihun W, Tolosa T (2010) Prevalence of Bovine Fasciolosis and Economic Importance due to Liver Condemnation at Kombolcha Industria Abattoir, Ethiopia. The Internet J Vet Med 8: 1-7.

27. Mesfin AY (1999) Study on the prevalence of bovine fasciolosis and morph Metric analysis of liver fluke populations in North Gondar area, Ethiopia. DVM Thesis, Faculty of Veterinary Medicine, Addis Ababa University, Debre Zeit, Ethiopia. 